\title{
DOI: https://dx.doi.org/10.21879/faeeba2358-0194.2021.v30.n63.p16-29 \\ A MULHER NA LEGISLAÇÃo EDUCACIONAL PARAENSE NA TRANSIÇÃO DO IMPÉRIO PARA A REPÚBLICA
}

\author{
Monika Reschke* \\ Secretaria Municipal de Educação \\ https://orcid.org/0000-0002-4756-9179 \\ João Lúcio Mazzini** \\ Secretaria de Estado de Educação \\ https://orcid.org/0000-0003-0697-3834 \\ Alberto Damasceno*** \\ Universidade Federal do Pará \\ https://orcid.org/0000-0003-1620-6735
}

\section{RESUMO}

Este artigo analisa a legislação educacional paraense a partir do regulamento da instrução pública no Império, Portaria de 29 de abril de 1871, fazendo um paralelo com o Decreto no 149 , de 7 de maio de 1890, primeiro do período republicano. A indagação foi se houve avanços nos direitos femininos relativos à instrução pública nesses documentos legais? Para responder traçamos os objetivos de identificar as principais semelhanças e diferenças nas legislações mencionadas; verificar o processo de inserção da mulher tanto como discente quanto docente no sistema público de instrução e detectar as principais características da educação feminina. Trata-se de uma pesquisa histórica, bibliográfica e documental. Após seleção e análise das fontes com base em Franco (2018), foi possível inferir que houve uma maior participação das mulheres na instrução a partir do advento da República, inclusive com o direito de voto e candidatura a cargo no Conselho Superior de Instrução Publica.

Palavras-chave: legislação educacional; instrução pública; educação feminina.

\section{ABSTRACT}

\section{THE WOMAN IN PARAENSE EDUCATIONAL LEGISLATION IN THE TRANSITION FROM THE EMPIRE TO THE REPUBLIC}

This article analyzes the paraense educational legislation from the regulation of the public instruction in the Empire, Ordinance of 29 of April of 1871, making a parallel with the Decree $n^{0} 149$ of 7 of May of 1890, first of the republican period. The question was whether there were advances in women's rights

\footnotetext{
* Mestra em Currículo e Gestão da Escola Básica pela Universidade Federal do Pará (UFPA). Técnica em Educação da Secretaria de Estado de Educação do Pará (SEDUC/PA) e professora da Secretaria Municipal de Educação (SEMED) de Ananindeua, Pará, Brasil. E-mail: reschke.monik@gmail.com

** Mestre em Currículo e Gestão da Escola Básica pela Universidade Federal do Pará (UFPA). Professor da Secretaria de Estado de Educação (SEDUC/PA). Belém, Pará, Brasil. Servidor do Arquivo Público do Estado do Pará. E-mail: jlmazzinidacosta@gmail.com

*** Doutor em Educação pela Pontifícia Universidade Católica de São Paulo (PUC/SP). Professor da Universidade Federal do Pará (UFPA). Belém, Pará. Brasil. E-mail: albertod@ufpa.br
} 
regarding public education in these legal documents? In order to answer, we outlined the objectives of identifying the main similarities and differences in the aforementioned legislation; to verify the process of insertion of women both as a student and as a teacher in the public education system and to detect the main characteristics of female education. It is a historical, bibliographical and documentary research. After selecting and analyzing the sources based on Franco (2018), it was possible to infer that there was a greater participation of women in education since the advent of the Republic, including the right to vote and stand for office in the Higher Council for Public Instruction.

Keywords: educational legislation; public instruction; female education.

\section{RESUMEN}

\section{LA MUJER EN LEGISLACIÓN EDUCATIVA PARAENSE EN LA TRANSICIÓN DEL IMPERIO A LA REPÚBLICA}

Este artículo analiza la legislación educativa paraense a partir del reglamento de la instrucción pública en el Imperio, Orden del 29 de abril de 1871, haciendo un paralelo con el Decreto no 149 del 7 de mayo de 1890, primero del período republicano. La pregunta era si hubo avances en los derechos de las mujeres en materia de educación pública en estos documentos legales. Para dar respuesta, delineamos los objetivos de identificar las principales similitudes y diferencias en la legislación antes mencionada; verificar el proceso de inserción de la mujer tanto como alumna como docente en el sistema educativo público y detectar las principales características de la educación femenina. Es una investigación histórica, bibliográfica y documental. Luego de seleccionar y analizar las fuentes con base en Franco (2018), se pudo inferir que hubo una mayor participación de las mujeres en la educación desde el advenimiento de la República, incluyendo el derecho a votar y a postularse en el Consejo Superior de Instrucción Pública. Palabras clave: legislación educativa; instrucción pública; educación femenina.

\section{Introdução ${ }^{1}$}

Partimos da análise da educação da mulher e do magistério como profissão essencialmente feminina. Situamos este artigo no âmbito de uma investigação histórica que buscou compreender o projeto de instrução e formação das mulheres subjacente à Portaria de 29 de abril de 1871 (PARÁ, 1871) e ao Decreto no 149, de 7 de maio de 1890 (PARÁ, 1890), com o intuito de resgatar a luta das mulheres pelo direito à educação e à profissionalização por meio do magistério.

10 estudo foi realizado seguindo todos os cuidados éticos que os pesquisadores devem levar em consideração durante a execução da pesquisa, sem negligenciar as bases teóricas e o cuidado com a análise das fontes.
A mulher, ao longo da história, sempre precisou de muita luta para ter acesso a escolaridade e participação no mercado de trabalho. Há algumas décadas, estudos referentes à questão do gênero vêm tomando uma importância significativa, principalmente na educação. Acompanhando um movimento de caráter internacional, que tomou impulso na década de 1970, também no Brasil surgiram, nesta época, grupos de estudo no meio acadêmico que passaram a pesquisar questões sobre a mulher ou a refletir sobre as relações homem/mulher em nossa sociedade (LOURO, 1994).

Em meio aos estudos sobre gênero, Louro (1994) faz referência às pesquisas de Scott 
(1990) apresentadas no artigo "Gênero: uma categoria útil de análise histórica”, no qual essa autora constrói sua definição de gênero na intenção de propor, principalmente aos historiadores, uma ferramenta com potencial analítico. Para Scott (1990), o gênero é um elemento constitutivo de relações sociais fundadas sobre as diferenças percebidas entre os sexos. Dada essa conclusão, pergunta-se: onde ou como se observaria esse elemento? Para Scott (1990 apud LOURO, 1994, p. 32), são muitos os segmentos na sociedade em que se observa a diferença entre os sexos, nomeados da seguinte forma:

[...] nos símbolos culturalmente invocados por uma sociedade; nos conceitos normativos que interpretam esses símbolos e que usualmente estão expressos nas doutrinas religiosas, educacionais, científicas, políticas e jurídicas; na política, nas instituições sociais e na própria organização social, e por fim, nas identidades subjetivas, ou seja, 'nas maneiras pelas quais as identidades de gênero são realmente construídas' (Scott, ob. cit., p. 15) pelos sujeitos concretos. (LOURO, 1994, p. 32).

Outro elemento também relevante nessa análise de gênero refere-se à afirmação de que este é "um primeiro modo de dar significado as relações de poder" (LOURO, 1994, p. 33). Dessa forma,

[...] uma vez que os conceitos de gênero que atravessam uma sociedade acabam por estruturar tanto a percepção quanto a organizaçãoconcreta e simbólica- da vida social, decorre daí que 'gênero torna-se envolvido na concepção e na construção do poder em si mesmo' (Scott, ob. cit. pp. 14-16). Portanto, segundo essa autora, o gênero seria um campo no qual foi e é vivida a história, e, para os(as) historiadores(as), um elemento que pode provocar não só novas questões, mas novas respostas para velhas questões, além de colocar novos ativos e visíveis sujeitos que usualmente têm estado escondidos nas análises mais tradicionais. (LOURO, 1994, p. 33).

Dessa forma, falar em gênero é uma forma de enfatizar o caráter social e, portanto, histórico, das concepções baseadas nas percepções das diferenças sexuais. Os inúmeros trabalhos dedicados a investigar gênero contribuem enormemente para o entendimento de uma dimensão importante das relações sociais e suas variações ao longo da história (STERNS, 2017).

Nesse sentido, este trabalho vem com a necessidade de levantar mais pesquisas nessa área, com o intuito de contribuir para os estudos de gênero, que a cada dia vêm dando maior visibilidade a essa causa, apoiando essa luta, que para a historiografia contemporânea é de grande valia, levando à reflexão da luta da mulher ao longo da história como uma pessoa de direitos e não só de deveres. Objetiva-se neste trabalho analisar a legislação educacional paraense à luz do regulamento da instrução pública da província do império, a portaria de 29 de abril de 1871 (PARÁ, 1871), fazendo uma comparação com o Decreto $\mathrm{n}$ - 149, de 7 de maio de 1890 (PARÁ, 1890), decreto este que vem a ser o primeiro do período republicano no Pará. Para nortear este estudo nos perguntamos: houve avanços nos direitos femininos relativos à instrução pública nesses documentos, visto que se passaram 19 anos desde o último regulamento no Império até o primeiro decreto da República?

Diante dessa indagação procuraremos identificar as principais semelhanças e diferenças nessas legislações, verificando como se deu o processo de inserção da mulher como aluna e como professora no sistema público de instrução nos dois períodos, final do Império e início da República. As fontes documentais foram selecionadas após busca no Arquivo Público do Estado do Pará (APEP), e, após sua análise, nos permitimos produzir inferências a respeito da situação da mulher no contexto educacional durante o período acima citado.

\section{A instrução pública na transição do Império para a República}

Com a independência do Brasil em relação a Portugal em 1822, a nova nação brasileira teve 
necessidade de se organizar como Estado e de promulgar uma Constituição própria, fato que fortaleceu também o debate sobre a exigência de um novo modelo de escola. Nesse contexto, Dom Pedro I, em 1823, inaugurou a Assembleia Nacional Constituinte e Legislativa e, no discurso de sua inauguração, "assinalou a necessidade de uma legislação especial sobre instrução pública" (SAVIANI, 2014, p. 11). A partir de então, a sociedade brasileira passou por um processo de modernização, com a criação de algumas universidades, faculdades e escolas técnicas, que vieram a contribuir significativamente com a expansão do ensino superior e profissional. Segundo Nascimento (1999), nesse período foram criadas várias instituições, dentre as quais se destacam: o Liceu de Artes e Ofícios de São Paulo, em 1873; o Liceu Imperial de 1838, em São Paulo; o Colégio D. Pedro II no Rio de Janeiro; a Escola Normal de Niterói, ideia que, posteriormente, se expandiu para outras localidades brasileiras.

Apesar de um certo esforço do Governo Imperial em instituir leis para promover o acesso ao ensino no país, isto se deu muito lentamente durante a primeira metade do século XIX, e padecendo de problemas graves como a

[...] falta de preparo (a tentativa de resolver esse problema com a criação de escolas normais ainda não surtira efeito e vinha sendo objeto de críticas constantes), parca remuneração e pouca dedicação dos professores; a ineficácia do método lancasteriano atribuía, sobretudo, à falta de instalações físicas adequadas à prática do ensino mútuo; e a ausência de fiscalização por parte das autoridades do ensino, o que tornava frequente nos relatórios a demanda pela implantação de um serviço de inspeção das escolas. (SAVIANI, 2014, p. 17).

Vale destacar a ineficácia do método lancasteriano ou de ensino mútuo que consistia, segundo Nunes (2008), na estratégia de o professor ensinar a lição para os discentes mais adiantados e inteligentes para que depois estes ensinassem aos alunos mais atrasados, os quais eram divididos em vários pequenos grupos. 0 método, desenvolvido na Inglaterra no final do século XVIII e início do século XIX por Andrew Bell e Joseph Lancaster, fundava-se na ideia de que

[...] qualquer número de estudantes pode formar uma classe, sem limite a um número determinado. [...] Desta maneira, cada classe tem um número apropriado de lições. A sua atenção se ocupará simplesmente com um objeto, e os estudantes de uma classe não se devem misturar ou sentar-se com os outros de outra classe. Os meninos, aprendendo o alfabeto, aprenderão a escrever as letras na areia ou na lousa. Logo que um estudante tiver excedido a primeira classe, aprenderá a fazer seu alfabeto, em qualquer classe que estiver, e escreverá na lousa aquilo que ler ou soletrar nas suas lições. Se estiver na classe de duas letras, escreverá palavras de duas letras; se na de três letras, palavras de três letras. (LANCASTER, 1823, p. 13-14).

Como se vê, mesmo com alguns avanços, a instrução pública necessitava de uma reforma mais ampla, pois o governo garantia apenas o acesso à escola de primeiras letras sem a garantia da continuidade dos estudos. Ao final do Segundo Império, já se manifestava a vontade de expandir o ensino técnico e superior em outras regiões para além do Sudeste, como também se discutia a criação de um Ministério exclusivo para a instrução pública. ${ }^{2}$

No entanto, com o fim do Império e o início da República, diversos fatos transformaram a sociedade brasileira, como o elevado crescimento econômico, a transição do trabalho escravo para o trabalho assalariado e, sobretudo, a busca pela construção de uma identidade nacional, para a qual era essencial uma educação pública e massiva, responsável pela moralização e civilização do povo, com a finalidade de fortalecer o novo regime político que se instaurava naquele momento.

2 Após reformulação da política educacional da União, ficou reestabelecido o Ministério da Instrução Pública no ano de 1890. Com isso se "tornaria dever do Governo Federal, promover e estimular o ensino primário, secundário e profissional em todo o País, com acordos entre União, estados e municípios, bem como subsídios para escolas particulares. Será a Lei Orçamentária de 1923 que permitirá a reorganização da instrução secundária e superior; e a reformulação da administração federal de ensino" (ALMEIDA, Jane Maria, 2009, p. 108). 
O movimento de renovação da escola primária empreendido pelos primeiros governos republicanos teve um profundo significado político, social e cultural. Tratava-se não apenas de sua difusão para o meio popular e de democratização do acesso à leitura e escrita - instrumentos culturais cada vez mais valorizados nas sociedades urbanas e nos regimes republicanos -, mas, também, da implantação de uma instituição educativa comprometida com os ideais republicanos e com as perspectivas de modernização da sociedade brasileira. (SAVIANI, 2014, p. 50).

Assim, é possível afirmar que o projeto educacional estava em consonância com o próprio projeto político-social da nação brasileira, o que exigia um caráter de urgência na sua implantação, na medida em que a expansão da instrução pública nos moldes republicanos em todo o território nacional era considerada essencial para a consolidação dos ideais do novo regime.

\section{A instrução voltada para mulheres}

No início do Império, com a chegada da família real, surgiram inovações no que concerne à educação feminina a partir da criação de escolas leigas para as mulheres da elite. Segundo Aranha (1994), o ensino era ministrado por preceptoras de origem europeia que ensinavam nas residências das alunas. Este ensino abrangia noções básicas de leitura, escrita, matemática e doutrina cristã. Em que pese a existência dessa instrução inicial, a preocupação central da época era desenvolver habilidades domésticas que permitissem à mulher ser uma boa mãe e uma esposa dócil.

Desde 1549 o ensino no Brasil era focado exclusivamente na catequização e civilização, pelos primeiros religiosos que aqui desembarcaram. A educação pensada estava sintonizada com a Igreja Católica e com o governo português, que se afinava com o objetivo de contribuir para a salvação da alma do índio, e civilizá-lo, no intuito de formar cidadãos tementes e Deus, mas que servissem para seus objetivos de colonização (POMPA, 2002). O europeu português que aqui chegou trazia em sua bagagem suas tradições, suas culturas, padrões, fé, que foram disseminados na formação de um novo povo. Em sua tradição, de uma sociedade patriarcal e androcêntrica, o povo português expõe o seu modo de viver ao mostrar como criar seus filhos e filhas.

Esses eram os modelos de família e de cultura que por aqui desembarcaram e perpetuaram. A educação no Brasil Colônia era direcionada somente para os homens. As mulheres não tinham acesso aos colégios. Essa característica também seguiu para o Império, em que havia também o domínio da Igreja, que exercia o controle da sexualidade feminina, na medida em que a mulher era vista como propensa ao pecado e devia obediência a um homem que, em um primeiro momento era seu genitor e, posteriormente, seu esposo. 0 controle da sexualidade da mulher por meio do matrimônio se dava pelo "interesse de fazer da família o eixo irradiador da moral cristã" (DEL PRIORE, 1989, p. 16).

Segundo Mariano (2013), o caminho percorrido pelas mulheres na história do Brasil, desde a chegada das primeiras portuguesas, constituiu-se de uma via tortuosa. Essas mulheres tiveram que viver encarceradas por um lado pelo patriarcalismo, e por outro pelas determinações religiosas. Elementos estes suficientes para sufocarem qualquer tipo de anseio feminino que estivesse além dos afazeres domésticos e da preocupação com a reprodução.

De acordo com Gondra e Schueler (2008), na sociedade brasileira oitocentista os espaços domésticos e familiares eram lócus de educação e instrução, geralmente transmitidas pelas mães, criadas e outras mulheres das famílias, ou, ainda, pela ação de professores particulares e preceptoras, contratadas pelas camadas mais abastadas para a educação de meninos e meninas.

As meninas e mulheres das elites seguiam a mesma finalidade de modelo de formação na aprendizagem de saberes dirigidos à adminis- 
tração da vida familiar, bem como a aquisição de normas de conduta e hábitos de civilidade e sociabilidade, tão apropriados para uma cultura urbana e burguesa europeia, que tinha como requisitos a aprendizagem de línguas estrangeiras, sobretudo a francesa, além da música, do canto e da dança de salão (GONDRA; SCHUELER, 2008).

Durante o período do Império brasileiro, ainda que as mulheres tenham começado a ter acesso à instrução das primeiras letras, eram desobrigadas de cursarem o ensino secundário, cuja função era preparar os homens para o ensino superior. 0 ensino superior foi uma realidade para as mulheres em 1879 , quando o governo imperial permitiu, condicionalmente, a entrada feminina nas faculdades.

Com a Assembleia Constituinte de 1823, surge a proposição de um projeto de instrução pública que visava ao ensino da juventude brasileira dos dois sexos. Alguns anos depois, em 1827, foi assinada pelo Imperador D. Pedro I a primeira norma relativa às escolas públicas primárias, que

[...] buscou dar forma ao disposto na Constituição Imperial de 1824 em que esta última estabelecia a instrução primária gratuita como componente da cidadania de acordo com o seu art. 179, XXXII. A lei geral de 1827 previa, em poucos artigos, a organização pedagógica, o currículo, o piso salarial igual para professores e professoras e a abertura de escolas. (CURY, 2017).

Nesse diploma legal, três artigos mencionavam as mulheres. 0 artigo 11 dispunha que haveria escolas de meninas nas cidades e vilas mais populosas nas quais os presidentes em conselho julgassem necessário. No artigo 12 era estabelecido que as mestras, com exclusão das noções de geometria e limitando a instrução da aritmética somente às suas quatro operações, ensinariam também as prendas que servem à economia doméstica, sendo nomeadas aquelas que, sendo brasileiras e de reconhecida honestidade, se mostrassem com mais conhecimentos nos exames feitos. Finalmente, $o$ artigo 13 determinava que as mestras receberiam os mesmos ordenados e gratificações concedidas aos mestres (BRASIL, 1827).

Contudo, mesmo que esses dispositivos legais contassem com a possibilidade de escolas para as mulheres, de professoras lecionando e de pagamentos iguais aos dos homens, é de se questionar as dificuldades enfrentadas por essas mulheres, visto que o pensamento dominante da época tinha a mulher como pessoa de pouca ou nenhuma formação, além da mentalidade, bastante difundida e aceita, de que a pessoa do sexo feminino deveria estar voltada para o cumprimento dos afazeres domésticos. Vidal (1996) constata que, ao longo do Império, para a mulher ser professora deveria ter virtudes morais e cristãs, além de ensinar conhecimentos práticos da vida doméstica. Nesse período prevaleciam os valores monárquicos que reproduziam o estereótipo feminino de "mulher frágil e abnegada" (ALMEIDA, Jane Soares, 1998, p. 114).

Dessa forma, a participação das mulheres no cotidiano escolar era norteada pela preocupação de desenvolver nelas habilidades manuais para trabalhos voltados à administração do lar. Todavia, ainda que a educação estivesse vinculada ao desenvolvimento de aptidões domésticas, é indubitável que este acesso à instrução foi um passo importante para que elas adentrassem no campo profissional.

A mentalidade de que a mulher era um ser dócil e submisso ainda permaneceu com o início da Primeira República, cujo estereótipo feminino era o da mulher sendo "rainha do lar" e dedicando-se integralmente à família e aos serviços domésticos (ALMEIDA, Jane Soares, 1998). No campo da medicina social, pesquisas "provavam" que essa fragilidade característica das mulheres era decorrência de fatores biológicos e naturais, pois, do ponto de vista da doutrina higienista, a atuação da mulher "não podia extravasar as fronteiras da casa e do consumo de bens e ideias que reforçassem a imagem da mulher-mãe. Por isso, sua presença nas catedrais da ciência era intolerável. A mulher intelectual dava mau exemplo às outras mulheres." (COSTA, 1979, p. 260). 
Por tudo isso é possível afirmar que na transição do Império para a Primeira República pouco mudou no que tange à instrução feminina, pois continuou a prevalecer a visão conservadora de supremacia dos homens, mesmo que houvesse uma preocupação dos republicanos em consolidar o novo regime e formar o cidadão por meio da instrução pública, função da qual a mulher também fazia parte preponderante.

\section{A instrução feminina paraense à luz das normas do final do Império e início da República}

A instrução da mulher passou por transformações que, mesmo de forma lenta, deram início a um processo de abertura do campo educacional e, com ele, ao ingresso no mercado de trabalho. Para verificarmos essas mudanças, utilizamos a legislação educacional vigente na transição do Império para a Primeira República, que foram a Portaria de 29 de abril de 1871 (PARÁ, 1871) e o Decreto no 149 , de 7 de maio de 1890 (PARÁ, 1890). Nestes documentos, entre os artigos de cada uma das normas, selecionamos aqueles que fazem alguma menção aos termos: mulher(es), menina(as), feminino. Esta seleção ocorreu mediante a utilização da análise de conteúdo à luz de Franco (2018), a partir do qual realizamos uma leitura inicial dos documentos, seleção das informações referentes ao objeto de estudo e posterior análise do material. Após esse processo chegamos ao Quadro 1 a seguir.

Quadro 1 - Principais dispositivos legais referentes à educação da mulher

\begin{tabular}{|c|c|}
\hline Norma & Conteúdo \\
\hline $\begin{array}{l}\text { Portaria de } \\
29 / 4 / 1871 \\
\text { (Dá novo } \\
\text { Regulamento } \\
\text { á Instrucção } \\
\text { pubica da } \\
\text { Provincia) }\end{array}$ & $\begin{array}{l}\text { "Art. 17. em cada freguezia da província haverá pelo menos uma escóla } \\
\text { publica primaria para cada um dos sexos. } \\
\text { Parágrafo único. suspender-se-há o ensino na escola, que não tiver sido } \\
\text { effectivamente frequentada em tres semestres, por quinze alumnos, ou por } \\
\text { dez alumnas. } \\
\text { Art. 18. Dando-se o caso figurado no § antecedente, e havendo no logar } \\
\text { escóla particular, que goze de bom conceito, o director geral, ouvido o } \\
\text { respectivo conselho de districto e com approvação do presidente da } \\
\text { província, contractará a admissão de alumnos pobres até o numero de dez } \\
\text { meninos ou oito meninas, mediante a subvenção mensal de dous mil réis } \\
\text { por cada um." } \\
\text { "Art. } 22 \text {. Nos logares em que não houver escóla publica do sexo feminino, } \\
\text { nem particular nos termos do art. 18, poderão professor publico, que fôr } \\
\text { casado, ensinar, mediante a gratificação do dito artigo, á certo numero de } \\
\text { meninas, fóra das horas regulares, incumbindo-se sua mulher de ensinar- } \\
\text { lhes á coser. } \\
\text { Art. } 23 \text {. Como ensaio poderão ser admittidos nas escólas do sexo feminino, } \\
\text { precedendo audiencia do conselho de districto, meninos até a idade de } \\
\text { oito annos, principalmente se forem irmãos, tios, primos, ou sobrinhos de } \\
\text { alguma das alumnas, do que se dará parte ao director geral." } \\
\text { "Art. 121. Aos alumnos-mestres e alumnas-mestras que concluírem o curso } \\
\text { normal, e forem approvados se lhes dará um diploma segundo o modelo } \\
\text { que for estabelecido, e lhes servirá de titulo de habilitação para entrarem } \\
\text { em curso para provimento de cadeira de } 1 \text { a entrancia, e para poderem ser } \\
\text { nomeados professores provisorios." }\end{array}$ \\
\hline
\end{tabular}


Decreto no 149 , de $7 / 5 / 1890$ (Dá Regulamento á Instrucção pubica)
“Art. $3^{\circ}$. 0 ensino secundário é dado: no Lyceu Paraense em um curso de preparatorios exigidos para a matricula nos cursos superiores da Republica. Nas escólas normaes para a formação de professores de ambos os sexos." "Art. 13. a direcção superior da instrucção publica constará de:

Um director geral.

Um secretario geral.

Um conselho superior de instrucção publica, assim composto: $[\ldots]$

IX- uma professora publica da capital eleita pelas suas collegas."

"Art. 32. são considerados aptos para votar nas eleições escólares:

II- as mulheres casadas.

III- as viuvas que vivam honestamente.

IV- as solteiras maiores de 21 annos, que estejam na mesma situação."

"Art. 36. as mulheres e os extrangeiros qualificam-se requerendo ao director geral e apresentando os documentos que, de comum, abonam ou provam os requisitos exigidos."

"Art. 57. as mulheres são elegíveis, quer para o conselho superior, quer para os conselhos escólares. Não podem porém ser eleitas para a vicepresidencia do conselho superior."

"Art. 92. nas escolas do sexo feminino, duas vezes por semana, á tarde, nos dias designados para os exercícios physicos dos rapazes, a ultima hora será empregada no ensino de prendas e trabalhos femininos, dando-se preferencia ao corte e confecção de peças do vestuario feminino e masculino e á custura."

"Art. 129. nenhuma professora ou professor de escóla popular poder-se-á ocupar de mais de quarenta alumnos."

"Art. 200. as escólas elementares do sexo feminino podem receber meninos até dez anos. As escólas populares podem tambem receber no curso elementar e no curso médio meninos até aquella edade, devendo as respectivas professoras dar disto conhecimento ás auctoridades competentes."

Fonte: Elaborado pelos autores deste artigo com base em Pará $(1871,1890)$.

Em uma análise preliminar, o que chama atenção é a maior complexidade da norma do período republicano, que conta com 218 dispositivos, enquanto a do Império é composta por 121 artigos.

Na Portaria do período monárquico, a referência feita à instrução feminina diz respeito ao ensino primário, enquanto o Decreto republicano menciona também o ensino secundário oferecido pelo Lyceu Paraense, como também se refere à formação de professores de ambos os sexos pela Escola Normal.

Era previsto pela Portaria de 1871 que nos lugares em que não houvesse o quantitativo suficiente de alunos frequentando - o mínimo de 15 meninos ou de 10 meninas - ao longo de três semestres, haveria a possibilidade de suspender o ensino da escola pública e a substituição desta, caso houvesse uma nas proximidades, por uma escola particular, a qual deveria apresentar um bom conceito. Após análise e aprovação dos órgãos responsáveis, o local poderia ser contratado por um valor de dois mil réis por cada aluno que frequentasse esse estabelecimento, sendo admitidos alunos pobres no máximo de dez meninos ou de oito meninas.

Destacamos que as escolas eram separadas para cada sexo, como também vale mencionar que a escola no período monárquico tinha ca- 
racterísticas diferentes das escolas atuais, funcionando em "espaços cedidos e organizados pelos pais das crianças e jovens aos quais os professores deveriam ensinar" (FARIA FILHO; VIDAL, 2000, p. 21) ou em espaços alugados pela administração pública, que na maioria das vezes era a própria residência do professor, 0 qual ministrava suas aulas para um grupo de alunos, sem uma divisão por séries.

Contudo, no período republicano, o ambiente escolar passou a ter uma nova formatação com a criação da escola primária denominada de graduada, que compreendia a "classificação homogênea dos alunos, várias salas de aula e vários professores, é uma invenção recente na história da educação brasileira. Esse tipo de escola primária, denominada Grupo Escolar, foi implantado no estado de São Paulo no início da década de 1890" (SOUZA, 2014, p. 35).

A criação dos grupos escolares também chegou ao Pará com o surgimento do primeiro grupo escolar no estado, sediado no município de Alenquer, em 1899, por meio do Decreto ${ }^{\circ}$ 722, de 10 de julho de 1899 (PARÁ, 1899).

O Grupo Escolar de Alenquer originou-se da reunião das escolas públicas isoladas, elementares e complementares existentes naquela localidade. As aulas foram organizadas em duas seções distintas: a feminina funcionava das 7 h30 às $11 \mathrm{~h} 30$ e a masculina das $13 \mathrm{~h}$ às 17 . Os corpos administrativo e pedagógico foram nomeados de acordo com o estabelecido no Regulamento Geral da Instrução Pública de 1899. Esse grupo, em 10 de fevereiro de 1900, foi denominado de Fulgêncio Simões. (FRANÇA, 2013, p. 7).

Nos casos em que não havia nem escola pública nem particular para atender o sexo feminino, o artigo 22 da norma monárquica assegurava que o ensino para as meninas poderia ser ministrado por professor público fora das suas horas regulares, mas exigia que este docente fosse casado e que a sua esposa ensinasse para as alunas a arte de costurar. Esta exigência reforçava a ideia de que caberia à mulher o papel "de ser 'esposa', 'mãe', 'rainha do lar', com atributos de docilidade, recato, fragili- dade, submissão e passividade" (DAMASCENO et al., 2018, p. 572).

No documento do Império verificamos um primeiro sinal do que seriam, anos depois, as escolas mistas, pois alguns estabelecimentos permitiam a presença de ambos os sexos. Também era permitida nas escolas femininas, após a aprovação das instâncias responsáveis, a presença de meninos com a idade máxima de até oito anos, tendo como critérios facilitadores para seu ingresso o fato de serem irmãos, tios, primos ou sobrinhos de alguma aluna. $\mathrm{Na}$ norma republicana essa mescla de sexos nas escolas ficou menos criteriosa, sendo permitido nas escolas elementares e no curso médio do sexo feminino a presença de meninos de até dez anos, tendo a professora a responsabilidade de informar às autoridades competentes o fato.

Percebemos também na norma do Império um início da profissionalização da mulher no campo do magistério, ao assegurar às alunas que concluíssem o curso normal, e que fossem aprovadas, um diploma que servia como título para sua habilitação para provimento de cadeiras e, com isso, poder ser nomeada como professora provisória.

$\mathrm{Na}$ norma republicana verificamos um modesto mas significativo alargamento dos direitos das mulheres, uma vez que, tratando da composição da direção superior da instrução pública, determinava que um dos seus componentes era uma professora pública da capital, a qual deveria ser eleita por suas colegas de profissão. Além disso, as mulheres aparecerem como aptas a votar nas eleições escolares, mas com algumas exigências como ser casada ou viúva que "vivesse honestamente", ou, se solteira, que tivesse mais de 21 anos e que também levasse uma "vida honesta". Outro direito conquistado foi a elegibilidade para o Conselho Superior e para os Conselhos Escolares, entretanto sem poder assumir o cargo de vice-presidente do conselho superior, como vislumbra o artigo 57.

Destacamos mais especificamente o Decreto no 149 , que criou o Regulamento Geral da 
Instrução Publica e Ensino Especial do Estado do Pará (PARÁ, 1890). O Regulamento Geral da Instrução Pública e Ensino Especial do Estado do Pará estava dividido em 15 capítulos, a saber: Da organização do ensino; Da direção geral do ensino; Do diretor geral; Do secretário geral; Do conselho superior; Dos conselhos escolares; Das eleições escolares; Da obrigatoriedade escolar; Do fundo escolar; Do ensino primário; Da criação das escolas e nomeações de professores; Dos professores públicos, seus direitos e deveres; Dos exames primários e do certificado de estudos primários; Da disciplina e economia escolar; e, finalmente, Das disposições gerais.

O ensino público estava dividido em primário, secundário e profissional ou técnico. O ensino primário seria ministrado nas escolas elementares, no Colégio do Amparo e no Instituto Paraense de Educandos e Artífices. 0 regulamento não afirmou que as mulheres pudessem participar como alunas ou professoras no Instituto paraense de educandos e artífices. Vejamos os pontos de interesse deste decreto: o art. 13 tratou da composição da Direção superior da instrução publica, órgão vinculado à diretoria geral de instrução publica que era responsável pela fiscalização do funcionamento da instrução; o art. 16, que tratou da nomeação para o cargo de DiretorGeral da Instrução Publica, é omisso quanto à possibilidade de serem nomeadas mulheres para o cargo. 0 inciso IX do mesmo artigo estabeleceu a eleição de uma professora entre as professoras do ensino primário para tomar assento na composição da direção.

0 art. 20 estabeleceu que o governador nomearia Secretário-Geral para auxiliar o Diretor-Geral. É omisso quanto a uma mulher exercer o cargo. 0 art. 27 tratou das atribuições e da eleição para preencher o Conselho Escolar municipal. 0 art. 32 estabeleceu que podiam votar nas eleições do conselho as pessoas que soubessem ler e escrever, as mulheres que podiam votar eram as que estavam incluídas nos seguintes parágrafos: II- As mulheres casadas; III- As viúvas que vivam honestamente; IV- As solteiras maiores de 21 anos que estejam nas mesmas condições.

0 art. 36 estabeleceu que as mulheres aptas a votar deveriam requerer as credenciais perante o Diretor-Geral e apresentar os documentos comprobatórios. 0 art. 57 estabeleceu que as mulheres eram vetadas para o cargo de vice-presidente do Conselho Superior. 0 art. 65 determinou que as crianças em idade escolar (dos 6 aos 13 anos) eram obrigadas a frequentar as escolas primárias nas cidades, vilas e povoações onde residam ou num raio de um quilômetro da escola. 0 Estado reconhecia que as crianças ensinadas em casa estavam desobrigadas de frequentar as escolas.

0 art. 86 tratou do ensino primário, do método de ensino, das disciplinas e do conteúdo das disciplinas. As escolas estavam divididas por sexo, todavia as disciplinas eram comuns aos sexos, como podemos ver no Quadro 2.

Quadro 2 - Disciplinas para o ensino primário nas escolas elementares

Disciplinas para o ensino primário nas escolas elementares, conforme 0 artigo 86

I - Ensino concreto das formas, cores, números dimensões, tempo, sons, qualidade dos objetos, medidas, seu uso e aplicação.

II - Geometria prática e noções sobre a mediação das áreas e capacidades.

III - Escrita e leitura.

IV - Ensino prático da língua materna, merecendo sobretudo atenção a construção correta das frases e a ortografia.

V - Aritmética prática compreendendo as quatro operações, frações decimais e ordinárias, sistema métrico, proporções, regra de três, cálculo de juros. Problemas concretamente formulados.

VI - Geografia do Estado e noções gerais da geografia do Brasil. Ideia geral da geografia universal. Fonte: Elaborado pelos autores deste artigo com base em Decreto no 149 (PARÁ, 1890). 
0 art. 88 criou a instrução primária integral que seria ministrada nas escolas populares. A duração seria de seis anos, sendo dividido dois anos para o curso elementar, dois anos para o curso médio e dois anos para o curso superior. As disciplinas do curso elementar são apresentadas no Quadro 3.

Quadro 3 - Disciplinas conforme o artigo 88

\section{DISCIPLINAS PARA AS ESCOLAS POPULARES}

I - Ensino concreto das formas, cores, números dimensões, tempo, sons, qualidade dos objetos, medidas, seu uso e aplicação. Pequenas lições de coisas.

II - Escrita e leitura.

III - Ensino prático da língua materna.

IV - Aritmética prática até a divisão por dois números. Problemas fáceis, sempre concretamente formulados.

V - Cultura moral. Comentário moral das narrativas do livro de leitura e dos atos da vida escolar.

\section{DISCIPLINAS DO CURSO MÉDIO}

I - Leitura e escrita. Ditados.

II - Língua portuguesa (no primeiro ano, gramática prática lida, explicada e largamente exemplificada; no segundo ano, primeiros rudimentos teóricos dos fatos da linguagem praticamente ensinados pelo método intuitivo; construç̃oes de frases).

III - Noções científicas das coisas, os três reinos da natureza, distinções entre cada uma delas. Usos gerais que o homem faz dos diversos elementos que o compõem.

IV- Aritmética prática até regra de três simples. Sistema métrico. Cálculos práticos e problemas concretos. Prática do sistema métrico.

V- Geometria prática. Construção prática das figuras planas no quadro preto. Medição prática das áreas e capacidades.

VI- Geografia. Estudo topográfico da escola e do sitio escolar, passando progressivamente a localidade e depois ao município, indicados não só os acidentes físicos como população, administração, produções, comércio e indústria. Primeiros elementos do desenho de mapas. Geografia física, política e econômica do Estado. Noções gerais de geografia física da terra.

VII- História da pátria. Leituras pelos alunos e comentários e explicações do mestre, depois repetidas por eles. Biografia de brasileiros ilustres da época colonial.

\section{DISCIPLINAS DO CURSO SUPERIOR}

I - Leitura expressiva e comentada dos autores brasileiros de boa nota. Declamação: trechos de prosa e verso, aprendidos de cor e recitados.

II - Exercícios de composição e estilo. Estudo teórico-prático da gramática portuguesa. Análise das proposições segundo o método das relações, desprezadas as classificações antigas.

III - Aritmética prática e teórica até as raízes quadradas e cúbicas excluídas os logaritmos. Noções práticas de escrituração mercantil. Cálculos comerciais.

IV- Geometria, estudo dos sólidos, representação gráfica dos sólidos no quadro preto. Rudimentos práticos de trigonometria e agrimensura.

V- Lições das coisas, noções de ciências práticas. Leitura e comentário de livros especiais. Exames de amostras e objetos próprios a estas lições, obtidos pelo mestre e pelos alunos. 
VI - Geografia geral. Noções sumárias de geografia física e política, especialmente da América.

VII - Geografia pátria. Estado geral da geografia física, econômica e política do país. Fronteiras. Estudo físico e econômico das principais bacias fluviais. Estudo de cada um dos Estados. Desenho, na pedra de cartas geográficas gerais e parciais do Brasil.

VIII - História universal. Ideias gerais sobre as grandes divisões da história. Principais nações e povos da antiguidade, da idade média e dos tempos modernos. Datas essenciais da cronologia.

IX - História do Brasil até a eliminação da monarquia.

X - Cultura cívica. Leitura e explicação da Constituição Federal e da do Estado.

XI - Disposições fundamentais das principais leis federais e do Estado. Noções sucintas e práticas do direito pátrio.

XII - Cultura moral. Observações sobre fatos da vida escolar, da vida prática e da história. Exposição dos principais deveres do homem para com a pátria, para com a humanidade e para com os seus cidadãos. Noções e exposição prática da solidariedade social e humana. Preceitos de civilidade.

Fonte: Elaborado pelos autores deste artigo com base no Decreto no 149 (PARÁ, 1890).

A essa divisão o art. 91 acrescentou a disciplina educação física. 0 conteúdo foi estabelecido nos itens listados no Quadro 4.

Quadro 4 - Conteúdo da disciplina educação física

I - Noções práticas de higiene particular sobre os alimentos, o vestuário, a casa, os exercícios, a distribuição do tempo de trabalho ou do repouso de cor e recitados.

II - Cuidados de asseio exigido e recomendados.

III - Exercícios físicos, marchas, saltos, movimento a pé firme e outros exercícios calistêni$\cos ^{*}$ feitos durante os recreios e ao menos duas vezes por semana em uma sessão especial de uma hora, à tarde.

IV - Jogos e brinquedos ao ar livre.

* Exercícios efetuados com o próprio peso do corpo.

Fonte: Elaborado pelos autores deste artigo com base no Decreto no 149 (PARÁ, 1890).

No art. 92 ficou estabelecido que a diferença entre meninos e meninas é que as meninas ao menos duas vezes na semana teriam, em vez de aulas de educação física, aulas de prendas e trabalhos femininos. A matéria principal era o curso de corte de fazendas e costura de peças que compunham o vestuário feminino e masculino. Estabeleceu o art. 93 os horários das aulas: nas escolas elementares iniciariam às 8 horas, findando às 12 horas; as escolas populares tinham duas sessões, pela manhã a entrada era as $7 \mathrm{~h} 30$ e a saída, às 11 horas, retornando pelo período da tarde, das 15 às 17 horas. Os livros, para serem adotados nas escolas, teriam que ser aprovados primeiramente pelo Diretor-Geral de ensino. E, por fim, o art. 225 estabeleceu que cabia ao governo fornecer o material permanente, bem como o material de consumo.

Descrito o protagonismo das alunas no ensino primário, vejamos o ensino secundário. Aqui destacamos o Lyceu Paraense e a Escola Normal. 0 regulamento é omisso quanto às mulheres ocuparem a direção do Lyceu e da Escola Normal. Novamente o regulamento é omisso quanto ao ingresso das mulheres como alunas no Lyceu Paraense. 0 ensino profissional foi ministrado no Instituto Paraense de Educandos e Artífices. 0 ensino, diferentemente do período anterior, é declarado leigo, o primário gratuito e obrigatório. Permitia-se o ensino pago.

No entanto, mesmo verificando alguns avanços legais no Decreto republicano, algumas características da instrução feminina foram mantidas sob o argumento da necessidade moral e social de se preservar a família, por esta razão o ensino das mulheres não se restringia aos conhecimentos escolares, mas deveria incluir o ensino de prendas domésticas. 
Ao compararmos as normas verificamos que, mesmo com a permanência de exigências como a obrigação do ensino doméstico, houve um avanço indiscutível dos direitos à educação feminina e a introdução da mulher no mercado de trabalho por meio da docência. A profissão de professora parecia ser ideal para as mulheres da época, visto que a docência era considerada uma extensão do lar e exigia dotes maternos, como amor e ternura, para educar as crianças. Mesmo com essa tentativa de equiparar a docência à maternidade, o acesso das mulheres à regência de uma escola revelou avanços conquistados ao longo da história do magistério primário feminino brasileiro que é, "principalmente, uma história de mulheres, de uma força invisível que lutou consciente e espontaneamente em defesa de suas crenças e de sua vontade" (ALMEIDA, Jane Soares, 1998, p. 77).

\section{Considerações finais}

Verificamos com este breve estudo que houve avanços dos direitos femininos relativos à instrução se compararmos o período do Império com o da República, o que pode ser observado a partir da Portaria de 29 de abril de 1871 (PARÁ, 1871) e do Decreto no 149 , de 7 de maio de 1890 (PARÁ, 1890).

Percebemos que nos dois períodos a instrução feminina se constituía por matrizes curriculares mínimas. A mulher deveria saber apenas o essencial para a sua vida pessoal, religiosa e conjugal, por esta razão as escolas se limitavam a transmitir-lhe conhecimentos elementares, além de ensinamentos cristãos e domésticos.

Constatamos também que, com a ampliação das escolas primárias, houve o crescimento da necessidade de professores para atender as demandas, principalmente na República, que necessitava de uma população letrada para consolidar o novo regime. Para atender essa demanda, as mulheres foram ingressando na docência, o que ocasionou uma feminização do magistério primário, apoiada pela ideia de que o ensino voltado às crianças teria uma relação direta com a maternidade e que as mulheres teriam as características essenciais para lidar com este público infantil, devido a sua doçura e generosidade.

Com a República, a legislação modificou a participação das mulheres no sistema educacional, possibilitando dois avanços importantes. 0 primeiro foi a participação de uma professora eleita entre as professoras primárias para compor o Conselho Superior de Instrução Publica, órgão de assessoramento do Diretor-Geral de Instrução Publica e de fiscalização do funcionamento do ensino público no Estado do Pará. Importante destacar que os municípios também constituíram seus Conselhos de Educação com a mesma competência estabelecida no Decreto.

O outro avanço, não menos importante, foi a diminuição da diferenciação do conteúdo das disciplinas ministrado para meninos e meninas nas escolas primárias. A questão salarial, pelo que vimos na legislação, não era um fator de diferenciação entre professoras e professores, configurando-se em outro avanço.

Em síntese, foi possível concluir que, ao longo da sua trajetória histórica, a mulher conquistou avanços sociais e profissionais, uma vez que, mesmo com um ensino limitado a conteúdos mínimos, conseguiu iniciar uma jornada com novas perspectivas, entre elas a de se tornar professora, iniciando seu processo de consolidação no mercado de trabalho.

\section{REFERÊNCIAS}

ALMEIDA, Jane Maria Fernandes de. A Reforma da Instrução Pública do Ceará de 1922: as diretrizes da política educacional do governo Justiniano de Serpa. 2009. 127 f. Dissertação (Mestrado em Políticas Públicas e Sociedade) - Centro de Estudos Sociais Aplicados, Universidade Estadual do Ceará (UECE), Fortaleza, 2009.

ALMEIDA, Jane Soares de. Mulher e educação: a paixão pelo possível. São Paulo: EdUNESP, 1998.

ARANHA, Maria Lucia de Arruda. Filosofia da Educação. São Paulo: Moderna, 1994.

BRASIL. Lei geral da instrução pública, de 15 de 
outubro de 1827. Manda crear escolas de primeiras letras em todas as cidades, villas e logares mais populosos do Imperio. Coleção de Leis do Império do Brasil, 1827. v. 1, pt. I (versão original). p. 71.

COSTA, Jurandir Freire. Ordem médica e norma familiar. Rio de Janeiro: Graal, 1979.

CURY, Carlos Roberto Jamil. Lei de Diretrizes e Bases da Educação Nacional: um caminho percorrido, um presente desafiante. 2017. Disponível em: http://www.apedu.org.br/site/2017/02/22/ lei-de-dir-e-bases-da-ed-nacional-um-caminhopercorrido-um-presente-desafiante-prof-jamilcury/. Acesso em: 23 ago. 2020.

DAMASCENO, Alberto et al. A mulher como professora primária: um desafio profissional na Primeira República. Retratos da Escola, Brasília, DF, v. 12, n. 24, p. 569-584, nov./dez. 2018. Disponível em: http://retratosdaescola.emnuvens.com.br/rde/ article/view/853/pdf. Acesso em: 23 ago. 2020.

DEL PRIORE, Mary. (org.). História das mulheres no Brasil. São Paulo: Contexto, 1989.

FARIA FILHO, Luciano Mendes de; VIDAL, Diana Gonçalves. Os tempos e os espaços escolares no processo de institucionalização da escola primária no Brasil. Revista Brasileira de Educação, Rio de Janeiro, n. 14, p. 19-34, maio/ago. 2000. Disponível em: https://www.scielo.br/j/rbedu/a/rjhxvFpJQ 97LDYVJxkXybbD/?format=pdf\&lang=pt. Acesso em: 20 ago. 2020.

FRANÇA, Maria do Perpétuo Socorro Gomes de Souza Avelino de. A implantação dos grupos escolares no estado do Pará. In: CONGRESSO BRASILEIRO DE HISTÓRIA DA EDUCAÇÃO, 7., 2013, Cuiabá. Anais […]. Cuiabá: UFMT, 2013.

FRANCO, Maria Laura P.B. Análise de conteúdo. 5. ed. Campinas, SP: Autores Associados, 2018.

GONDRA, José Gonçalves; SCHUELER, Alessandra. Educação, poder e sociedade no império brasileiro. São Paulo: Cortez, 2008.

LANCASTER, José. Sistema britânico de educação. Tradução de Guilherme Skinner. Porto: Tip. Da Viúva de Alvarez \& Filips, 1823.

LOURO, Guacira Lopes. Uma leitura da história da educação sob a perspectiva do gênero. Revista Projeto História, v. 11, p-31-46, nov. 1994.

MARIANO, Jorge Luís Mazzeo. A educação como forma de projeção feminina no Brasil colônia e império. In: CONGRESSO NACIONAL DE EDUCAÇÃO: EDUCERE, 11., 2013, Paraná. Anais [...]. Curitiba:
Pontifícia Universidade Católica do Paraná, 2013. p. 20953- 20965.

NASCIMENTO, Jorge Carvalho. A cultura ocultada ou a influência alemã na cultura brasileira durante a segunda metade do século XIX. Londrina: EdUEL, 1999.

NUNES, Maria Thetis. História da educação em Sergipe. Aracaju: Fundação Oviêdo Teixeira, 2008.

PARÁ. Portaria S/N, de 29 de abril de 1871. Coleções das Leis e dos Atos do Governo Provinciais do Pará. Tomo XXXIII. Belém: Tipografia do Diário do Grão-Pará, 1871.

PARÁ. Decreto no 149, de 07 de maio de 1890. Atos do Governo Provisório do Estado do Pará. Belém: Typ. do Diário Oficial, 1890. Disponível em: http://www.fcp.pa.gov.br/2016-12-13-19-43-03/ actos-do-poder-executivo-do-para-1890. Acesso em: 10 ago. 2020.

PARÁ. Decreto no 722, de 10 de julho de 1899. Manda que as escolas de Alenquer funcionem em grupo escolar. Belém: Imprensa Oficial do Pará, 1899.

POMPA, Maria Cristina. O lugar da utopia: os jesuítas e a catequese indígena. Novos Estudos CEBRAP, v. 64, p. 83-92, 2002.

SAVIANI, Dermeval. 0 legado educacional do "breve século XIX" brasileiro. In: SAVIANI, Dermeval et al (org.). 0 legado educacional do século XIX. 3. ed. Campinas, SP: Autores Associados, 2014. p. 7-26.

SCOTT, Joan. Gênero: uma categoria útil de análise histórica. Revista Educação e Realidade, v. 15, n. 2, p. 71-99, jul./dez. 1990.

SOUZA, Rosa Fátima de. Espaço da educação e da civilização: origens dos grupos escolares no Brasil. In: SAVIANI, Dermeval et al (org.). 0 legado educacional do século XIX. 3. ed. Campinas, SP: Autores Associados, 2014. p. 33-66.

STERNS, Peter N. História das relações de gênero. 2. ed. São Paulo: Contexto, 2017.

VIDAL, Diana Gonçalves. "Educação doméstica" e reforma da instrução pública do Distrito Federal. Cadernos de Pesquisa, São Paulo, n. 99, p. 3035, nov. 1996. Disponível em: http://publicacoes. fcc.org.br/index.php/cp/article/view/783/795. Acesso em: 23 ago. 2020.

Recebido em: 15/03/2021 Aprovado em: 26/07/2021

(cc) $\mathbf{\text { EY-NC }}$ Este é um artigo publicado em acesso aberto sob uma licença Creative Commons. 